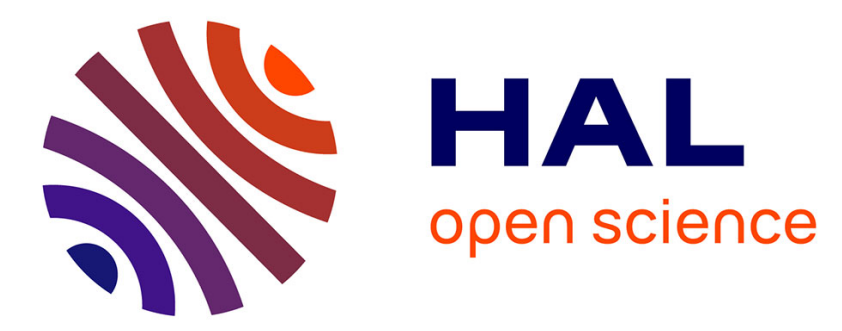

\title{
Adsorption of Hydrophobically Modified Polyacrylic Acid on a Hydrophobic Surface: Hysteresis Caused by an Electrostatic Adsorption Barrier.
}

J.G. Göbel, N.A.M. Besseling, M.A. Cohen Stuart, Celine Poncet-Legrand

\section{- To cite this version:}

J.G. Göbel, N.A.M. Besseling, M.A. Cohen Stuart, Celine Poncet-Legrand. Adsorption of Hydrophobically Modified Polyacrylic Acid on a Hydrophobic Surface: Hysteresis Caused by an Electrostatic Adsorption Barrier.. Journal of Colloid and Interface Science, 1999, 209 (1), pp.129-135. 10.1006/jcis.1998.5853 . hal-02695693

\section{HAL Id: hal-02695693 \\ https://hal.inrae.fr/hal-02695693}

Submitted on 1 Jun 2020

HAL is a multi-disciplinary open access archive for the deposit and dissemination of scientific research documents, whether they are published or not. The documents may come from teaching and research institutions in France or abroad, or from public or private research centers.
L'archive ouverte pluridisciplinaire HAL, est destinée au dépôt et à la diffusion de documents scientifiques de niveau recherche, publiés ou non, émanant des établissements d'enseignement et de recherche français ou étrangers, des laboratoires publics ou privés. 


\title{
Adsorption of Hydrophobically Modified Polyacrylic Acid on a Hydrophobic Surface: Hysteresis Caused by an Electrostatic Adsorption Barrier
}

\author{
J. G. Göbel,* N. A. M. Besseling,* M. A. Cohen Stuart,*,1 and C. Poncet; \\ *Laboratory for Physical Chemistry and Colloid Science, Wageningen Agricultural University, P.O. Box 8038, 6700 EK Wageningen, The Netherlands; \\ and $\ddagger$ Laboratoire de Physicochimie Macromoléculaire, Université Pierre et Marie Curie, CNRS URA $n^{\circ} 278$, \\ ESPCI, 10 rue Vauquelin, F-75231 Paris cedex 05, France
}

Received May 26, 1998; accepted August 31, 1998

The adsorption of hydrophobically modified polyacrylic acid (HM-PAAC) has been compared to the adsorption of unmodified polymers by means of reflectometry. The polymers were adsorbed onto a noncharged hydrophobic polystyrene surface.

The adsorption kinetics of both types of polymer is the same until a certain surface coverage. Then the unmodified sample shows a saturation while the hydrophobically modified polyacrylic acid continues to adsorb.

The adsorption behavior of the polyelectrolyte can be controlled by the $\mathrm{pH}$ and the ionic strength of the solution. For ionic strengths of $0.001 \mathrm{M} \mathrm{NaCl}$ the hydrophobically modified polymer shows a larger adsorbed amount at pH 3 to 4 compared to the unmodified polymer. At pH higher than 4 the differences are less significant. At higher ionic strength the amount of adsorbed material increases for both polymers.

While doing adsorption- desorption cycles a hysteresis-effect was detected. At the same $\mathrm{pH}$ the hydrophobically modified polymer sticks to the surface while the unmodified polymer is already desorbing completely. The hysteresis vanishes when the ionic strength of the solution is increased. $\odot 1999$ Academic Press

Key Words: adsorption kinetics; hydrophobically modified polyacrylic acid; electrostatic barrier.

\section{INTRODUCTION}

Water-soluble hydrophobically modified polymers (HMpolymers) are very important as thickening agents and stabilizers in dispersions and emulsions. One interesting subclass of HM-polymers is based on polyelectrolytes. The fact that their surface activity can be adjusted both chemically and by manipulating the ionic strength or the $\mathrm{pH}$ of the solution makes them powerful tools for many applications.

In most cases, the hydrophobic groups are alkyl chains grafted to the backbone of the polymer by chemical reaction. In water, these alkyl groups tend to associate, just like simple surfactants do (1), and they interact with added surfactants. In addition, the alkyl groups modify the adsorption properties of

\footnotetext{
${ }^{1}$ To whom correspondence should be addressed.
}

the polymers onto hydrophobic solids. While the bare polyelectrolyte backbone has no, or little, affinity for a hydrophobic surface, the HM-polymer absorbs more strongly (2). Understanding the adsorption behavior is important in the context of the use of HM-polymers as dispersants.

The central questions addressed by this work are (i) how is adsorption of a polyelectrolyte on a neutral surface modified by the presence of a small amount of hydrophobic "anchors" in the molecule, and (ii) how does the charge introduced on the surface by the adsorbing molecules affect the kinetics of the adsorption process. In a theoretical paper (3), we concluded that the adsorption of polyelectrolytes may sometimes be completely stopped by electrostatic repulsion well before the equilibrium situation is reached. As a result, there is in such cases no reversibility with respect to adsorption and desorption. In particular, one expects hysteresis with respect to variables controlling the electrostatic interaction ( $\mathrm{pH}$, ionic strength). As a model system, we chose polyacrylic acid (PAAc) and a dodecylated derivative (HM-PAAc) thereof. PAAc and its derivatives are frequently used in experimental investigations as model polyelectrolytes $(4,5)$.

The adsorption of polyelectrolytes on an uncharged surface is determined by a balance between electrostatics, tending to desorb the molecule from the surface, and the hydrophobic interaction. Because the hydrophobic groups are very dilute, their main effect will be to provide extra anchoring on the surface.

The electrostatic effect depends on two main factors (6).

- The charge of the polymer which is mainly dependent on the $\mathrm{pH}$ of the solution.

- The ionic strength of the solution which controls the range of electrostatic interactions.

The adsorption process of any polymer molecule can be divided into three consecutive steps (7).

- Transport of molecules toward the surface by convection and diffusion 
- Attachment of the polyelectrolyte molecules onto the surface

- Spreading or change in conformation of the adsorbed layer.

If the hydrodynamic conditions of the experiment are chosen well, the transport step can be conveniently described by a diffusive-convective equation. In stationary state and when the transport rate determines the kinetics of the adsorption, one can usually write (7):

$$
\frac{d \Gamma}{d t}=k\left(c_{b}-c_{s}\right)
$$

Here, $d \Gamma / d t$ is the measured adsorption rate, $c_{b}$ and $c_{s}$ stand for the bulk phase concentration and the "subsurface" concentration, respectively, and the transport coefficient $k$ is a function of the flow rate near the surface and the diffusion coefficient. The subsurface concentration is the concentration of free polymer in the immediate vicinity of the surface. For our experiment we use a wall-jet flow cell of known dimensions which gives well-defined transport conditions in the stagnation point. The value of mass transfer of the polymer at this point can be described by $(8,9)$

$$
k=0.77^{1 / 3} R^{-1} D^{2 / 3}(\nu \bar{\alpha} \operatorname{Re})^{1 / 3} .
$$

Here, $\nu$ is the kinematic viscosity, $R$ the radius of the inlet tube, $D$ the polymer diffusion coefficient, $\bar{\alpha}$ dimensionsless stream intensity parameter, and Re the Reynolds number.

If the molecules approaching the surface experience a barrier, the rate of attachment is lowered. In general, one expects the attachment to follow first order kinetics (rate coefficient $K_{1}$ ) with respect to $c_{s}$. Eliminating $c_{s}$, one finds that this leads to the following expression for the adsorption rate:

$$
\frac{d \Gamma}{d t}=\frac{c_{b}}{\frac{1}{k}+\frac{1}{K_{1}}} .
$$

Because we have polyelectrolytes adsorbing on a neutral surface, the most important cause of repulsion is the charge in previously adsorbed polymers. Calculations of $K_{1}$ as a function of net surface charge and ionic strength have been published before (3). These calculations have shown that at low ionic strength $K_{1}$ decreases sharply with increasing surface charge, i.e., with increasing adsorbed amount. As soon as the barrier becomes too high, adsorption stops altogether. At high ionic strength, adsorption may proceed until equilibrium is reached.

\section{EXPERIMENTAL}

\section{Substrate}

Silicon wafers, purchased from Aurel, were cut into rectangular pieces approximately $1 \mathrm{~cm}$ wide and $6 \mathrm{~cm}$ long. These

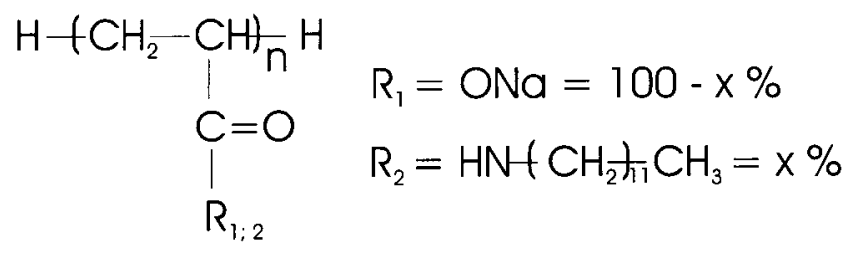

FIG. 1. Sketch of the HM-polymer chain, $x$ corresponds to the percentage of modifications.

strips were rinsed with toluene and ethanol (p.a. grade, Fa. Merck, Germany), respectively, and dried in a nitrogen gas stream. Then the wafers were inserted in an ozonizator for 20 $\min$. The ozonizator is a chamber in which a flow of oxygen is streaming past an UV-light source. The silicon carries a thin film $(2.4 \mathrm{~nm})$ of silicon dioxide.

The clean wafers were spincoated with a polystyrene of broad molecular weight distribution. The polystyrene was dissolved in toluene (concentration $13 \mathrm{~g} / \mathrm{l}$ ) and $300 \mu \mathrm{l}$ of the solution are used to coat the wafers. After spincoating at 2500 $\mathrm{rpm}$ for $12 \mathrm{~s}$ the wafers were removed from the spinner disk and dried in an oven at $100^{\circ} \mathrm{C}$ for $2 \mathrm{~h}$ to stabilize the film and to remove traces of solvent. This procedure leads to a polystyrene layer with a thickness of $48 \mathrm{~nm}$. Samples of the wafers were checked regularly measuring the film thickness with a Sentech SE 400 null ellipsomter.

\section{Polymer Samples}

Unmodified polyacrylic acid PAAc $\left(\mathrm{M}_{\mathrm{w}}=500.000 \mathrm{~g} / \mathrm{mol}\right)$ was purchased from Polysciences Inc., Warrington, PA.

The HM-PAAc samples were synthesized using the method of Wang et al. (10) PAAc with a molecular weight of 500,000 $\mathrm{g} / \mathrm{mol}$ was grafted with hydrophobic tails of N-dodecyl-acrylamide. Figure 1 shows a schematic sketch of the polymer.

The HM-PAAc sample refers to a polysodium acrylate in which 3\% ( $x=3$ in Fig. 1) of the carboxylic groups are converted into dodecyl-acrylamide groups. The degree of hydrophobic modifications were checked by NMR (11). From these measurements it is known that the hydrophobic modifications are randomly distributed along the hydrophilic backbone (11). It should be realized that samples prepared in this way will possess a certain heterogeneity both with respect to chain length (polydispersity in molar mass) and with respect to the degree of modification. On purely statistical grounds, even a perfectly random grafting reaction will yield a mixture of chains, varying in degree of substitution (chemical heterodispersity).

Stock solutions of the polymers were diluted for the adsorption experiments down to $10 \mathrm{mg} / \mathrm{l}$, using deionized water adjusted to $\mathrm{pH} 3$ with $\mathrm{HCl}$. For higher $\mathrm{pH}$ values the ionic strength of the solution was controlled by adding sodium chloride (p.a. grade, Fa. Merck, Germany). 


\section{Adsorption Measurements}

The adsorption of the HM-polymer was measured by means of reflectometry, as described in detail in (12) and (13); polymer solutions were applied to the substrate by a continuous flow in a stagnation-point flow cell. The experiments were performed at room temperature $\left(22^{\circ} \mathrm{C}\right)$ and, unless mentioned otherwise, at an ionic strength of $0.001 \mathrm{M} \mathrm{NaCl}$ and a $\mathrm{pH}$ of 3 . In the following these kinds of experiments will be named "undisturbed adsorption."

\section{Adsorption/desorption Measurements}

This kind of experiment begins like the undisturbed adsorption experiment as described above. Because especially with HM-PAAc adsorption continued to increase with time we decided to interrupt the adsorption after $300 \mathrm{~s}$ and rinse with solvent at the same $\mathrm{pH}$ and ionic strength. However this is a time chosen arbitrarily and the adsorbed amount has definitely not reached the equilibrium value for the HM-PAAc.

After rinsing the adsorbed layer of polymer with solvent the $\mathrm{pH}$ of the solvent was increased to induce a charge on the PAAc and start the desorption process. The desorption process was monitored until a stable value for the reflectometer readings was established and then the $\mathrm{pH}$ of the solvent was changed back to $\mathrm{pH} 3$ to establish the same conditions as in the beginning of the adsorption experiment and rinsed again for some time. In this way we can exclude any influence of the $\mathrm{pH}$ change on the refractive index of the solution. (For a better understanding of this adsorption-desorption cycle refer to Fig. 5). In the following we will call this the adsorption-desorption experiment.

\section{RESU LTS}

In Fig. 2 we present the adsorbed amount $(\Gamma)$ as a function of the adsorption time for PAAc and HM-PAAc and for various values of the $\mathrm{pH}$, in undisturbed adsorption experiments.

Clearly, the HM-polymer shows a somewhat larger adsorbed amount over the whole $\mathrm{pH}$ range. The difference is pronounced at low $\mathrm{pH}$ but becomes less at $\mathrm{pH}$ higher than 4. At low $\mathrm{pH}$ there is also a marked difference in the shape of the adsorption curves. At the beginning of the adsorption process both polymers seem to adsorb at the same adsorption rate: the slopes of the curves are nearly the same. After about $50 \mathrm{~s}$ the adsorption curves show a change in slope. Whereas the curves for PAAc rather abruptly reach a saturation plateau at low $\mathrm{pH}$, the adsorption of the HM-sample continues, showing a smooth transition region. Saturation of the surface is not really established during the experimental time range; even after long times there is still a small but finite slope. At pH 5 it becomes difficult to be sure about differences between PAAc and HM-PAAc because of some drift of the signal baseline.

To see the difference in adsorption behavior more clearly the undisturbed adsorption experiment was carried out with vari-

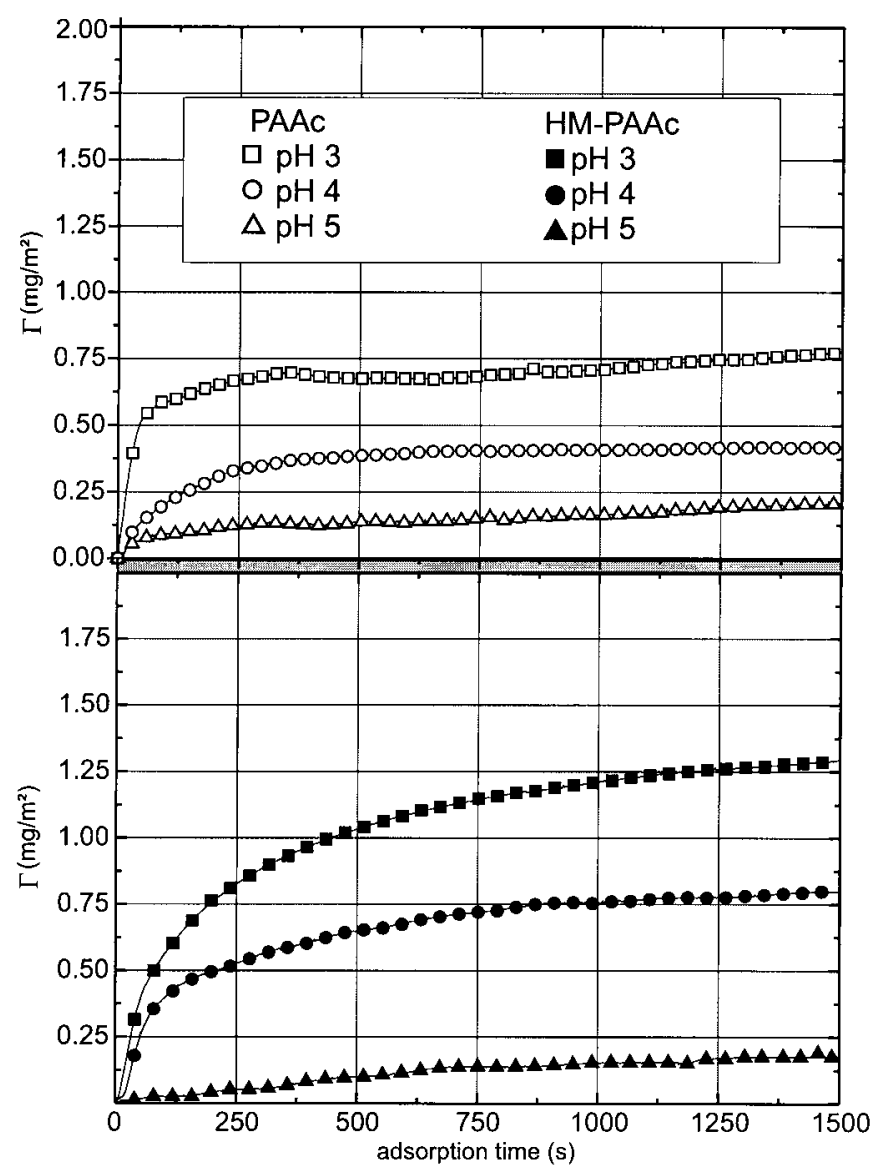

FIG. 2. Influence of $\mathrm{pH}$ variation on the undisturbed adsorption. Adsorption of PAAc and HM-PAAc at various $\mathrm{pH}$ as measured by reflectometry. Ionic strength $0.001 \mathrm{M} \mathrm{NaCl}$; polymer concentration, $10 \mathrm{mg} / \mathrm{l} . \square, \mathrm{PAAc}$ at $\mathrm{pH} 3$; $\bigcirc$, PAAc at $\mathrm{pH} 4 ; \triangle$, PAAc at $\mathrm{pH} 5 ; \mathbf{\square}, \mathrm{HM}-\mathrm{PAAc}$ at $\mathrm{pH} 3 ; \boldsymbol{\bullet}, \mathrm{HM}-\mathrm{PAAc}$ at $\mathrm{pH}$ 4; $\boldsymbol{\Delta}$, HM-PAAc at pH 5.

ous concentrations of PAAc and HM-PAAc, again at $\mathrm{pH} 4$ and constant ionic strength of $0.1 \mathrm{M} \mathrm{NaCl}$. In Fig. 3 we present the results of this experiment; the horizontal axis is rescaled by multiplying the elapsed experimental time by the polymer concentration. As can be seen from Eq. [1], this superimposes the various adsorption curves as long as the adsorption process is transport limited. Thus, from the nearly identical initial slopes of the adsorption curves for both polyelectrolytes we can conclude that there is no difference in initial adsorption rate. As in Fig. 2, a remarkable difference in the shape of the curves can be seen after the initial stages of adsorption. Beyond $\Gamma=0.4 \mathrm{mg} / \mathrm{m}^{2}$ HM-PAAc continues to adsorb while the adsorption of PAAc stops completely. The derivations in the slope at the beginning of the adsorption experiments which can be detected in Fig. 4 for concentrations of $60 \mathrm{mg} / \mathrm{l}$ can be explained by interactions of the polymer molecules in the solutions. We think that due to the high concentration the adsorption process is slowed down because the rate of polymer molecules being transported to the interface is too high in the first stage of the process. This effect has been detected only 


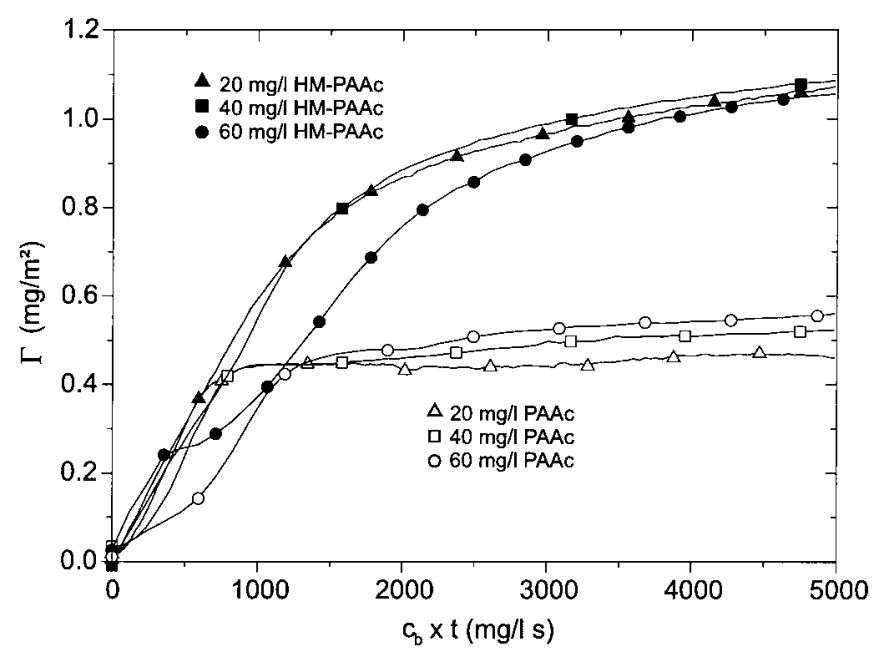

FIG. 3. Influence of the hydrophobic modification on the undisturbed adsorption of PAAc. Adsorption of PAAc and HM-PAAc as measured by reflectometry. Ionic strength $0.1 \mathrm{M} \mathrm{NaCl}$ at $\mathrm{pH} 4 . \triangle, 20 \mathrm{mg} / \mathrm{l} ; \square, 40 \mathrm{mg} / \mathrm{l} ; \bigcirc$, $60 \mathrm{mg} / \mathrm{l} \mathrm{HM}-\mathrm{PAAc} ; \boldsymbol{\Delta}, 20 \mathrm{mg} / \mathrm{l} ; \boldsymbol{\square}, 40 \mathrm{mg} / \mathrm{l} ; \bullet$, $60 \mathrm{mg} / \mathrm{l}$ PAAc.

during adsorption experiments with high polymer concentrations.

The undisturbed adsorption kinetics of HM-PAAc for two different ionic strengths of the solution are shown in Fig. 4 for the same period as in Fig. 2. Here, it is obvious that for both ionic strengths the adsorption curve reaches no real plateau but continues within the time observed.

If the data obtained so far represent true equilibrium, one should expect that only the final conditions determine the adsorbed mass. Hence, preparing a sample in a different way should eventually lead to the same adsorption. This is attempted in the next set of experiments, described above under

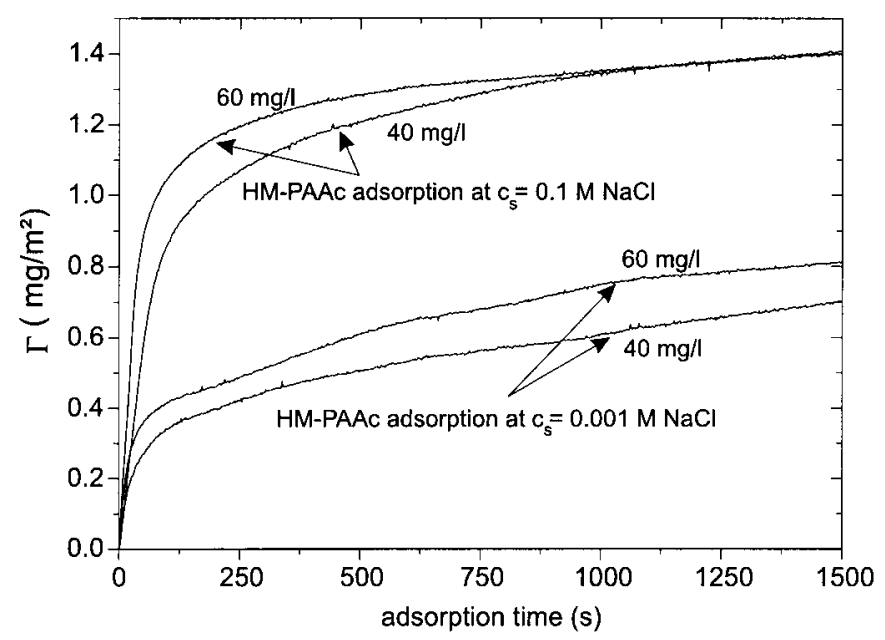

FIG . 4. Influence of ionic strength on the undisturbed adsorption. Adsorption of HM-PAAc (40 and $60 \mathrm{mg} / \mathrm{l}$ ) at two different ionic strengths of the solution at $\mathrm{pH} 4$ as measured by reflectometry. The two upper curves refer to an ionic strength of $0.1 \mathrm{M} \mathrm{NaCl}$, the two lower curves to a strength of 0.001 $M \mathrm{NaCl}$.

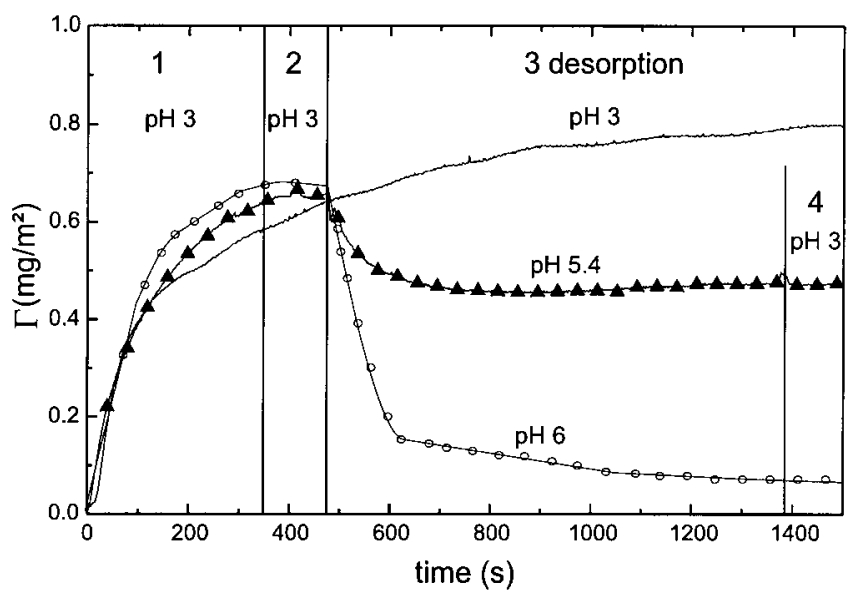

FIG. 5. Adsorption-desorption experiment of HM-PAAc on polystyrene surfaces measured by reflectometry. Adsorption of $10 \mathrm{mg} / \mathrm{HM}-\mathrm{HAAc}$ at $\mathrm{pH}$ 3 ( $\Delta$ ) (section 1), rinsing with water $\mathrm{pH} 3$ (section 2), changing to $\mathrm{pH} 5.4$ (section 3), and rinsing with water $\mathrm{pH} 3$ (section 4). Adsorption of $10 \mathrm{mg} / \mathrm{l}$ HM-PAAc at $\mathrm{pH} 3(\mathrm{O})$ (section 1), rinsing with water $\mathrm{pH} 3$, changing to $\mathrm{pH}$ 6 (section 3), and rinsing with water $\mathrm{pH} 3$ (section 4). Undisturbed adsorption measurement of $10 \mathrm{mg} / \mathrm{l} \mathrm{HM}-\mathrm{PAAc}$ at constant $\mathrm{pH} 3$ for comparison (without markers). Ionic strength during all measurements constant at $\mathrm{c}_{\mathrm{s}}=0.001 \mathrm{M}$ $\mathrm{NaCl}$.

the term adsorption-desorption experiment. In Fig. 5 we present a typical result for such an adsorption-desorption cycle. For comparison, we give in this figure also the original curve for undisturbed adsorption of HM-PAAc at the same conditions (curve without markers).

The curves show always the same slope at the first step of the experiment. The rinsing with the pure solvent stops the adsorption but no significant desorption takes place. After switching to some specific higher $\mathrm{pH}$ value the polymer starts to desorb. This higher $\mathrm{pH}$ of the desorption phase is in the following denoted as the $\mathrm{pH}$ of the experiment. Finally, the desorption stops and the original $\mathrm{pH}$ of 3 is restored, in order to undo changes in the signal due to $\mathrm{pH}$-dependency of the refractive index increment. In Fig. 6 we compare the adsorbed amounts of undisturbed adsorption experiments after $300 \mathrm{~s}$ (lower curves) with those from adsorption-desorption experiments, as described above, for both PAAc and the HM-PAAc at $0.001 \mathrm{M} \mathrm{NaCl}$.

The results of the undisturbed adsorption curves (filled markers) are very similar for the two polymers, except at $\mathrm{pH} 3$ where the HM polymer shows considerably higher adsorption. For both polymers, no adsorption is detectable for $\mathrm{pH}>7$. The adsorption-desorption results (open markers) of both polymers present higher adsorptions at the same $\mathrm{pH}$. The difference between the result after $300 \mathrm{~s}$ of the undisturbed adsorption and the results of the adsorption-desorption experiment is much higher for the HM polymer. Hence, there is a clear hysteresis in these $\mathrm{pH}$-cycles, the extent of which is strongly enhanced by the dodecylgroups.

From the data in Fig. 6, it seems very likely that the incor- 
poration of hydrophobic groups in the polymer helps to stabilize the polymer in its adsorbed state (so that it does not so easily desorb when charged up), but does not really promote the spontaneous adsorption at high $\mathrm{pH}$. This suggests the presence of an adsorption barrier of electrostatic origin. If this hypothesis is correct, the addition of an electrolyte should remove or at least diminish the hysteresis.

A new set of adsorption-desorption experiments was therefore carried out with the HM polymer, but now at higher ionic strength. The results are given in Fig. 7. Here we compare the hysteresis at an ionic strength of $0.1 \mathrm{M} \mathrm{NaCl}$ to that at 0.001 $M \mathrm{NaCl}$ as was shown in Fig. 6. Due to the higher ionic strength the adsorption-desorption results are somewhat higher, but a really large effect is observed for the undisturbed adsorption curve, which has increased substantially over the entire $\mathrm{pH}$ range. The hysteresis, so evident at $0.001 \mathrm{M} \mathrm{NaCl}$, has almost disappeared.

\section{DISCUSSION}

What scenario arises from these data? At low $\mathrm{pH}$, the polymers are very weakly charged. Under these conditions, they can adsorb at the hydrophobic substrate. In this range of $\mathrm{pH}$, the hydrophobically modified polymer has a significantly higher adsorption at the hydrophobic surface, which may be ascribed to the extra anchoring ability. When the $\mathrm{pH}$ is increased, the polymers acquire more charge. In solution, they will then appear as macro-ions surrounded by a diffuse cloud of counterions. When such a macro-ion approaches the neutral surface, the available volume for the counterions will be reduced, and this leads to an effective repulsion. The counterion density and, hence, the repulsion will increase further when polymer accumulates at the surface. For stabilizing the adsorbed layer, the effect of the counterions has to be balanced by

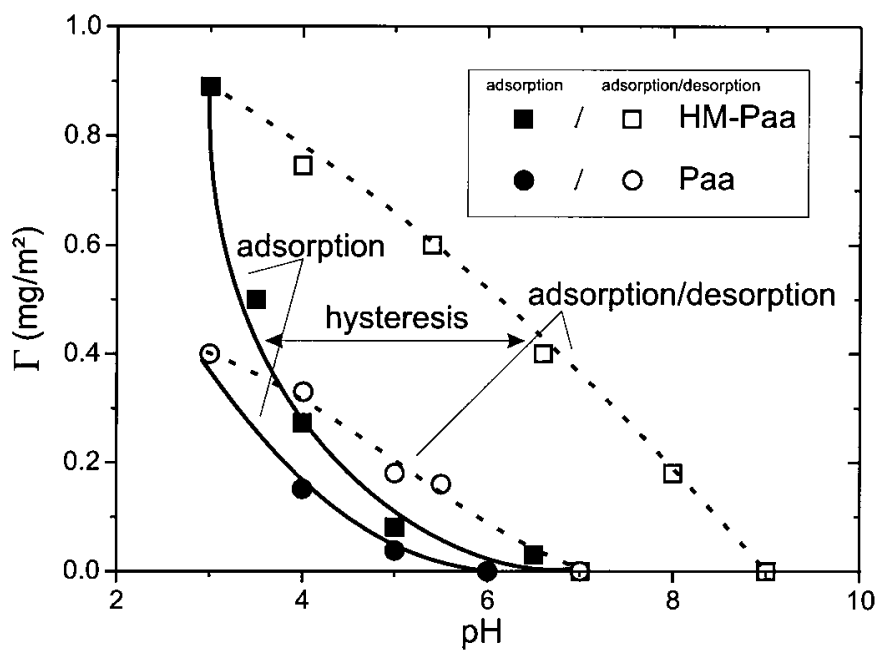

FIG. 6. Adsorption-desorption hysteresis of HM-PAAc compared to PAAc. Concentration of HM-polymer $10 \mathrm{mg} / \mathrm{l}$, ionic strength $0.001 \mathrm{M} \mathrm{NaCl}$.

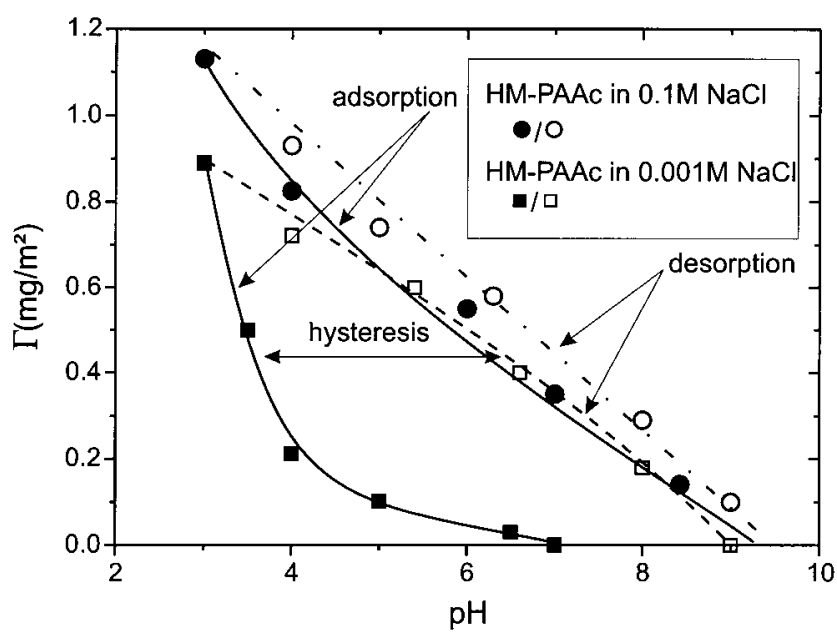

FIG. 7. Influence of ionic strength on adsorption of HM-PAAc at polystyrene surfaces showing the electrostatic barrier. $\boldsymbol{Q}$, adsorption; $\bigcirc$, desorption at $0.001 \mathrm{M} \mathrm{NaCl} ; \mathbf{\square}$, adsorption; $\square$, desorption at $0.1 \mathrm{M} \mathrm{NaCl}$.

short range attraction between the polymer and the substrate; in the present system, hydrophobic interactions play that role. This combination of a short range attraction and a repulsion of longer-variable - range creates a polymer-surface interaction curve with a maximum located very close to the surface; the maximum will be particularly pronounced when the ionic strength is low and the polymer charge density high.

When a polymer layer is first formed (e.g., at low pH), after which the charge is increased by increasing the $\mathrm{pH}$ as in the adsorption-desorption experiments, an amount of polymer will desorb until the anchoring interaction and the electrostatic repulsion are just balanced. The layer is then in equilibrium. However, if an initially bare surface is exposed to the polymer solution at $\mathrm{pH}>3$, a long range repulsive barrier arises as soon as some adsorption has occurred. The following molecules must overcome this barrier before they can attach and gain anchoring energy. As a result adsorption becomes prohibitively slow and the equilibrium will also be reached very slowly. For the present system, at $0.001 \mathrm{M} \mathrm{NaCl}$, PAAc is highly charged at $\mathrm{pH}>7$ and we cannot detect any adsorbed polymer at the surface (refer to Fig. 6). There is also no detectable adsorption for HM-PAAc at this $\mathrm{pH}$ and ionic strength. However we cannot remove an adsorbed layer of HM-PAAc previously at $\mathrm{pH} 3$ completely by simply changing the $\mathrm{pH}$ to 7 as demonstrated in the adsorption-desorption experiment (refer to Fig. 6 ). This is a demonstration of the pronounced adsorption barrier.

As is also clear from the data, the kinetically controlled adsorption curve is insensitive to the presence of the hydrophobic groups. This is to be expected as it is the charge which controls the adsorption rate. In contrast, the equilibrium adsorbed amount, obtained after some desorption, is strongly enhanced by the presence of dodecyl groups. The differences disappear when salt is added: this removes the barrier and the 


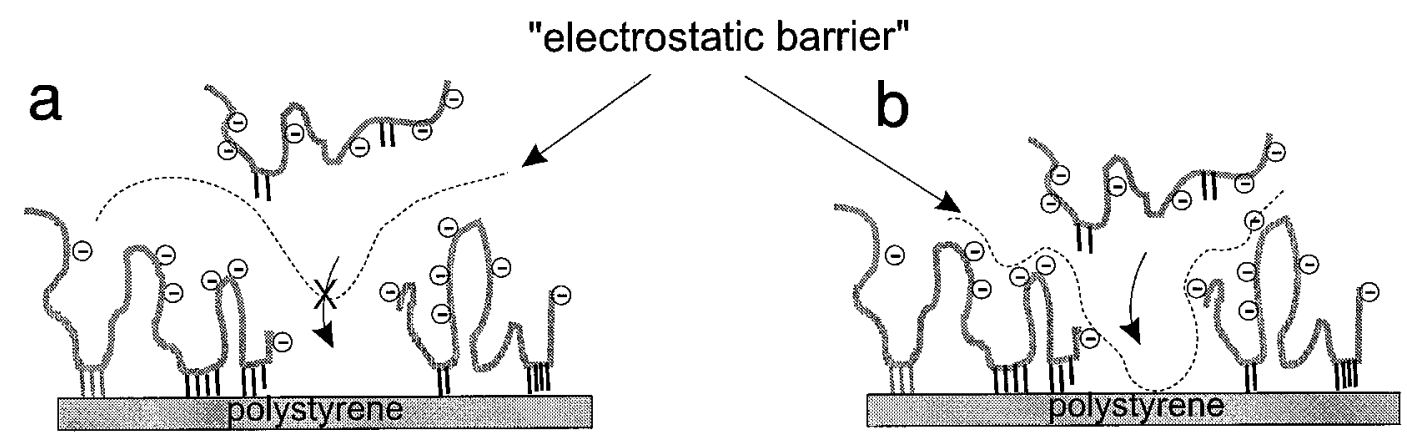

FIG. 8. Sketch of adsorption of HM-PAAc on polystyrene: (a) low ionic strength, (b) high ionic strength.

layer can equilibrate at all $\mathrm{pH}$. Figure 8 explains these effects pictorially.

Hysteresis effects like the one reported here have been observed by various authors. However, with the present data we were able to provide a clear explanation in terms of attachment kinetics and to clarify the roles of long range repulsion and short range attraction. A similar kinetic limitation effect was noted by de Laat et al. (14) in the adsorption of polydisperse PAAc on oxidic surfaces. Since the repulsion experienced by a polyelectrolyte near a charged surface increases with its molar mass, the longest chains were rigorously excluded from the surface, thus leading to a kinetically determined surface fractionation. The authors explained their data in terms of a kinetic analysis using, like us (3), mean field arguments. Although the use of a mean field model for an isolated polymer with its counterion cloud in the electric field of the surface is questionable, these calculations provide a first estimate of the barrier effect.

In the kinetic curves (Figs. 2-4) it can be seen that the adsorption rate for the HM polymers remains finite (although small) up to very long times, whereas the nonmodified PAAc saturates completely on these time scales. This is also the case for higher ionic strengths where the hysteresis effect has disappeared. One is therefore inclined to ascribe less sharp saturation of HM-PAAc to the presence of the dodecyl groups. Presumably, this is an effect of the chemical heterodispersity due to which the sample contains a distribution of molecules differing in surface affinity. Molecules with a higher fraction of dodecyl groups will adsorb more strongly and displace molecules with a lower degree of alkylation. As the fraction of such molecules in the overall sample may be very low the displacement process will be very slow; electrostatic repulsion may even further slow this down. However, we can conclude that chemical heterodispersity is not the cause of the adsorptiondesorption hysteresis because otherwise the hysteresis could not disappear upon adding salt.

\section{CONCLUSIONS}

Hydrophobically modified polyacrylic acid has a higher affinity for an uncharged hydrophobic surface than non- modified polyacrylic acid. However, the adsorbed amount is not always determined by affinity alone. At low ionic strength, the rate of attachment of polyelectrolyte molecules is strongly reduced by an electrostatic barrier which is, in turn, determined by the surface coverage. As a result, strong kinetic limitation of the adsorption occurs and the adsorbed amount of modified and unmodified polyacrylic acid are virtually the same.

However, the difference between modified an unmodified polyacid becomes apparent when adsorption is measured over a $\mathrm{pH}$ cycle. In such a cycle, adsorption-desorption hysteresis occurs as a consequence of the attachment barrier. It is the extent of hysteresis which is affected strongly by the hydrophobic modification. We conclude that it is the adsorbed amount obtained after increasing the charge that corresponds most closely to equilibrium.

The hysteresis disappears when salt is added $(0.1 \mathrm{M} \mathrm{NaCl})$ because this suppresses the electrostatic interactions. Hence, under these conditions the adsorbed layer can be considered as (approximately) equilibrated.

Finally, the HM-polymers have a chemical heterodispersity which is not present in pure polyacrylic acid. This chemical heterodispersity is responsible for the smooth bending and the higher slope at longer times of the observed adsorption curves. This heterodispersity does not seem to contribute to the hysteresis.

\section{ACKNOWLEDGMENT}

This project was financially supported by the European Union HCM program under Contract CMRX-CT94-0655.

\section{REFERENCES}

1. McCormick, C. L., Nonaka, T., and Johnson, C. B., Polymer 29, 731 (1988).

2. Liang, W., Bognolo, G., and Tadros, Th. F., Langmuir 11, 2899 (1995).

3. Cohen Stuart, M. A., Hoogendam, C. W., and de Keizer, A., J. Phys.: Condens. Matter 9, 7767 (1997).

4. Plavsic, M., Cosovic, B., and Rodic, S., Colloid Polymer Sci. 274, 578 (1996).

5. Sastry, N. V., Séquaris, J. M., and Schwuger, M. J., J. Colloid Interface Sci. 171, 224 (1994). 
6. Fleer, G. J., Cohen Stuart, M. A., Scheutjens, J. M. H. M., Cosgrove, T., and Vincent, B., in "Polymers at Interfaces," Chapman \& Hall, London/ New York, 1993.

7. Cohen Stuart, M. A., "Macromolecular Adsorption: A Brief Introduction," in "Biopolymers at Interfaces" (M. Malmsteen, Ed.), Dekker, New York, 1998 , in press.

8. Dabros, T., and van de Ven, T. G. M., Colloid Polymer Sci. 261, 694 (1983)

9. Cohen Stuart, M. A., and Fleer, G. J., Annu. Rev. Mater. Sci. 26, 463 (1996).

10. Wang, T. K., Iliopoulos, I., and Audebert, R. in "Water soluble polymers: Synthesis, solution properties and applications" (S. W. Shalaby, C. L.
McCormick, and G. B. Butler, Eds.), ACS Symposium Series 467, Chap. 14, 218, Amer. Chem. Soc., Washington, 1991.

11. Magny, B., Lafuma, F., and Iliopoulos, I., Polymer 33, 3151 (1992).

12. Dijt, J. C., Cohen Stuart, M. A., Hofman, J. E., and Fleer, G. J., Colloids Surf. 51, 141 (1990).

13. Dijt, J. C., Cohen Stuart, M. A., and Fleer, G. J., Adv. Colloid Interface Sci. 50, 79 (1994).

14. de Laat, A. W. M., van den Heuvel, G. L. T., and Böhmer, M. R., Colloids Surf. A. Phys. Eng. Aspects. 98, 61 (1995). 